\title{
P-glycoprotein and survivin simultaneously regulate vincristine- induced apoptosis in chronic myeloid leukemia cells
}

\author{
PALOMA SILVA DE SOUZA ${ }^{1,2}$, FLAVIA DA CUNHA VASCONCELOS ${ }^{1,2}$, FLAVIANA RUADE DE SOUZA REIS ${ }^{1,2}$ \\ GABRIELA NESTAL DE MORAES $^{1,2}$ and RAQUEL CIUVALSCHI MAIA ${ }^{1,3}$ \\ ${ }^{1}$ Laboratório de Hemato-Oncologia Celular e Molecular, Programa de Pesquisa em Hemato-Oncologia Molecular; \\ ${ }^{2}$ Programa de Pós Graduação Stricto Sensu em Oncologia; ${ }^{3}$ Serviço de Hematologia, Hospital do Câncer I, \\ Instituto Nacional de Câncer (INCA), Brazil
}

Received April 13, 2011; Accepted May 23, 2011

DOI: $10.3892 /$ ijo.2011.1103

\begin{abstract}
Overexpression of P-glycoprotein (Pgp/ABCB1) in tumor cells is associated with a classic phenotype of multidrug resistance (MDR). Moreover, some members of the inhibitor of apoptosis protein (IAP) family, such as survivin, contribute to an apoptosis-resistant phenotype, by inhibiting chemotherapyinduced cell death and promoting MDR. By using Western blotting, qRT-PCR, Annexin V and immunofluorescence assays we have demonstrated a relationship between Pgp and survivin in a prior sensitive chronic myeloid leukemia (CML) cell line (K562). A high dose of vincristine induced a concomitant overexpression of Pgp and survivin, which was associated with a low apoptotic index in the K562 cell line. In addition, we observed a cytoplasmic co-localization of Pgp and survivin, suggesting a functional association between these two proteins in apoptosis control by a common mechanism. In summary, our data suggest that Pgp and survivin should be analyzed in aggregate because they may have significant impact on drug resistance in CML cells.
\end{abstract}

\section{Introduction}

Chemotherapy plays a fundamental role in cancer treatment. However, diverse types of cancer do not respond to treatment due to the multidrug resistance (MDR) phenotype. Classical MDR is characterized by the overexpression of ATP-binding cassette $(\mathrm{ABC})$ drug transporter proteins $(1,2)$. Some of these proteins, such as P-glycoprotein (Pgp, ABCB1, MDR1), multidrug resistance-associated protein (MRP1, ABCC1) and breast cancer resistance protein (BCRP, ABCG2), have been closely

Correspondence to: Dr Raquel C. Maia, Laboratório de HematoOncologia Celular e Molecular, Programa de Hemato-Oncologia Molecular, Coordenação Geral Técnico-Científica, Instituto Nacional de Câncer, Praça da Cruz Vermelha 23, Centro, Rio de Janeiro, RJ, CEP 20230-130, Brazil

E-mail: rcmaia@inca.gov.br

Key words: P-glycoprotein, survivin, chronic myeloid leukemia, apoptosis resistance, multidrug resistance, cell death, vincristine related to poor treatment response and prognosis in many malignancies (3-6).

The MDR phenotype has been mostly associated with overexpression of Pgp, which promotes resistance to a broad spectrum of structurally unrelated cytotoxic drugs (7). Generally, some epithelial-derived tumors may express Pgp and become intrinsically resistant. However, drug resistance can also be acquired during the course of chemotherapy by tumors that are initially sensitive to treatment $(8,9)$. To support this notion, we have recently shown that modifications in Pgp status, caused by a diversity of drugs, can alter the desirable effect induced by a specific chemotherapeutic drug during the treatment of chronic myeloid leukemia (CML) patients (10).

Pgp is commonly located in the plasma membrane, in which Pgp functions as a drug efflux pump. Nevertheless, some studies have demonstrated its localization in intracellular sites such as the nuclear envelope and in the membrane of cytoplasmatic organelles (11). These studies suggest that Pgp function is related to cellular protection against toxic agents, independently of its localization.

Currently, an additional role for Pgp concerning apoptosis resistance has been proposed. Some studies suggest the involvement of Pgp in apoptosis inhibition induced by different stimuli $(12,13)$. Pgp was able to inhibit caspase-mediated apoptosis induced by anti-Fas and ultraviolet radiation in different cell lines (13-15). Pgp expression may contribute to spontaneous apoptosis in leukemia patient cells (16). Moreover, subpopulations of leukemic CD $34^{+}$cells have a lower rate of spontaneous apoptosis than leukemic CD34- cells due to overexpression of Pgp (17).

Nevertheless, several mechanisms may promote MDR in tumor cells besides overexpression of Pgp. It is known that disruption of apoptotic pathways may contribute to MDR establishment. Studies have shown that increased expression of inhibitor of apoptosis proteins (IAPs), such as survivin and XIAP, induces the MDR phenotype during tumor progression $(1,18)$. Overexpression of survivin has been detected in various neoplasms, and has been associated with a more clinical aggressive tumor behavior in neuroblastoma, and colorectal and gastric cancers (19). In addition, overexpression of survivin is correlated with an increase of resistance and a reduction of apoptosis rate (20). 
In an interesting way, Liu et al (21) demonstrated in the Pgp-positive breast cancer-resistant MCF-7/Adr cell line that the downregulation of Pgp expression could also suppress survivin mRNA expression, whereas the reverse impact was not observed in the Pgp-negative MCF-7 cell line. The same group recently confirmed these results by demonstrating that survivin transcription was associated with Pgp overexpression through the PI3K/ Akt pathway in the same cell lines (22). Therefore, the purpose of our study was to investigate whether an antineoplastic drug could induce the MDR phenotype in a sensitive leukemia cell line and to determine a possible relationship between Pgp and survivin. We observed that concomitant overexpression and localization of $\mathrm{Pgp} / A B C B 1$ and survivin promoted a reduction in K562 cell death, which suggests a functional association between these two proteins in apoptosis control by a common mechanism.

\section{Materials and methods}

Drug. Vincristine sulfate (Tecnocris ${ }^{\circledR}$ ) was provided by Zodiac (São Paulo, Brazil). This drug was diluted in RPMI-1640 prior to use.

Cell culture. The human CML K562 cell line, derived from a CML patient positive for the Philadelphia chromosome $\left(\mathrm{Ph}^{+}\right)$, was obtained from the American Type Culture Collection (ATCC), Manassas, VA, USA. Cells were cultured in RPMI1640 medium (LGC Biotechnology) supplemented with $10 \%$ heat-inactivated fetal bovine serum $\left(\mathrm{Gibco}^{\circledR}\right)$ and maintained at $37^{\circ} \mathrm{C}$ under $5 \% \mathrm{CO}_{2}$ in a humidified atmosphere.

Analysis of cell viability. Cell viability was evaluated by a modified MTT (USB) assay (23). K562 cells $\left(10^{5} / \mathrm{ml}\right)$ were treated with vincristine for $24 \mathrm{~h}$, at final concentrations of 0.03 , $0.06,0.6,1.0$ and $2.0 \mu \mathrm{M}$. Briefly, cells were plated onto 96 -well plates in $200 \mu \mathrm{l}$ growth medium and $20 \mu \mathrm{l}$ of MTT $(5 \mathrm{mg} / \mathrm{ml}$ in phosphate-buffered saline) reagent were added to each well. After incubation with MTT for $4 \mathrm{~h}$ at $37^{\circ} \mathrm{C}$, the supernatant was removed and $150 \mu \mathrm{l}$ of DMSO (dimethyl sulfoxide) (SigmaAldrich, St. Louis, MO, USA) were added to dissolve the formazan salt. Absorbance at $492 \mathrm{nM}$ was measured with an ELISA reader (DTX 800 Multimode Detector from Beckman Coulter, Fullerton, CA, USA), and the percentage of cell viability was assessed as: (absorbance of vincristine treated cells/absorbance of untreated cells) $\mathrm{x} 100$. The concentrations and experiments were done in triplicate.

Cell cycle analysis. Following treatment with $0.6 \mu \mathrm{M}$ vincristine at various time points $(0,2,6,8,18$ and $24 \mathrm{~h}), \mathrm{K} 562$ cells were harvested, washed in PBS (phosphate-buffered saline), and incubated with $500 \mu \mathrm{l}$ of propidium iodide (PI) staining solution (PI $50 \mu \mathrm{g} / \mathrm{ml}$ diluted in citrate buffer $4 \mathrm{mM}$ and $0.3 \%$ Triton X-100) and RNAse (ribonuclease A $100 \mu \mathrm{g} / \mathrm{ml}$ diluted in citrate buffer $40 \mathrm{mM}$ ) for $15 \mathrm{~min}$ at room temperature. DNA content was determined by collecting 10,000 events for cell cycle analysis using a CyAn ADP analyzer flow cytometry and Summit v4.3 software (Dako, USA) (24).

Apoptosis detection. K562 cells were harvested at 0, 2, 6, 8, 18, and $24 \mathrm{~h}$ after exposure to vincristine $(0.6 \mu \mathrm{M})$. The percentage of apoptotic cells was assessed using the Annexin V assay (Genzyme Diagnostics, Cambridge, MA, USA). Cells were stained with FITC-labeled Annexin V as previously described (25). Briefly, cells were washed in PBS and pellets were incubated with $5 \mu \mathrm{g} / \mathrm{ml}$ Annexin V, $5 \mu \mathrm{g} / \mathrm{ml} \mathrm{PI}$, and binding buffer for $15 \mathrm{~min}$ in the dark, on ice. The drug-induced apoptotic index was analyzed by flow cytometry, and the results were calculated as a percentage of apoptosis in the presence of the drug subtracting apoptosis in the absence of the drug.

Determination of caspase-3 expression by flow cytometry. This experiment was also performed incubating K562 cells with $0.6 \mu \mathrm{M}$ vincristine for $0,2,6,8,18$ and $24 \mathrm{~h}$. Cells were permeabilized using a FACS lysing solution, washed in $0.5 \%$ Tween-20/PBS, and incubated with $1 \%$ BSA (bovine serum albumin, Sigma-Aldrich). Caspase-3 expression was measured after incubation for 30 min with PE-conjugated monoclonal antibody anti-caspase-3 (Becton-Dickinson, NJ, USA), according to the manufacturer's instructions. After 3 washing steps cells were fixed with $1 \%$ paraformaldehyde and analyzed using flow cytometry. The results were expressed as the percentage of caspase-3 positivity compared with untreated cells.

Determination of Pgp expression by flow cytometry. For analysis of Pgp membrane expression, K562 cells were incubated with $0.6 \mu \mathrm{M}$ vincristine for $0,2,6,8,18$ and $24 \mathrm{~h}$. Next, cells were incubated with $1 \%$ BSA for 15 min. Pgp membrane expression was measured after incubation for $30 \mathrm{~min}$ with PE-conjugated monoclonal antibody anti-Pgp (clone UIC2, Coulter, USA), according to the manufacturer's instructions. After three washing steps cells were fixed with $1 \%$ paraformaldehyde and analyzed using flow cytometry. The results were expressed as the ratio of mean of fluorescence intensity (MFI), obtained by dividing cells incubated with anti-Pgp by cells without anti-Pgp (10).

Western blotting. For pro-caspase-3, XIAP and survivin detection $\mathrm{K} 562$ cells were exposed to $0.6 \mu \mathrm{M}$ vincristine for $0,2,6$, 8,18 and 24 h. Pellets of $2 \times 10^{6}$ cells were washed three times with PBS and lysed in resuspension buffer $(40 \mathrm{mM}$ Tris- $\mathrm{HCl}$; $40 \mathrm{mM}$ EDTA; pH 7.5) and $10 \%$ SDS for $15 \mathrm{~min}$ at $100^{\circ} \mathrm{C}$. The total protein was determined using Bio-Rad protein assay solution, and $50 \mu \mathrm{g}$ of lysates were subjected to SDS-PAGE onto $15 \%$ polyacrylamide gels (acrylamide/bis-acrylamide $30 \% ; 25 \% \mathrm{H}_{2} \mathrm{O} ; 115 \mathrm{mM}$ Tris- $\mathrm{HCl}$ buffer $\mathrm{pH}$ 8.8; Temed; APS). After electrophoresis, proteins were transferred to Hybond-P membranes. The blots were blocked for $2 \mathrm{~h}$ at room temperature with $5 \%$ non-fat dry milk TBS containing $0.2 \%$ Tween-20 before incubation with antibodies against caspase-3 (1:500 dilution, BD Biosciences, San Jose, CA, USA), XIAP (1:1000 dilution, R\&D Systems, Minneapolis, MN, USA), survivin (1:1000 dilution, R\&D Systems), or $\beta$-actin (1:1000 dilution, Sigma-Aldrich) in the same solution. After three washing steps of 5 min each with TBS-Tween, blots were exposed to anti-mouse, anti-rabbit, or anti-goat IgG antibody conjugated with horseradish peroxidase (1:1000 dilution; GE Healthcare, Buckinghamshire, UK or Novus Biologicals, Littleton, CO, USA). Antibody complexes were visualized by the ECL detection system (GE Healthcare). The expression of caspase-3, XIAP and survivin was normalized with respect to $\beta$-actin as previously shown (26). 
Real-time quantitative PCR (TaqMan) analysis (qRT-PCR). This experiment was also performed incubating K562 cells with $0.6 \mu \mathrm{M}$ vincristine for $0,2,6,8,18$ and $24 \mathrm{~h}$. For Pgp/ABCBl or XIAP mRNA analysis, total RNA from treated cells was isolated using the guanidinium thiocyanate method (TRIzol Invitrogen, Carlsbad, CA). RNA was treated with DNAse (Ambion, Austin, TX) to eliminate contaminating DNA. cDNA was synthesized with the Ready-To-Go T-Primed first-strand kit (GE Healthcare, Piscataway, NJ). Pgp/ABCB1 and XIAP mRNA were amplified by qRT-PCR using probes obtained from Applied Biosystems (Foster City, CA). Real-time monitoring of PCR amplification of cDNAs was carried out using TaqMan Universal master mix (Applied Biosystems). Relative quantification of target gene expression was performed by employing a comparative $\mathrm{Ct}$ method using arithmetic formulas as described in the TaqMan user manual. $\beta$-actin probe (Applied Biosystems) was used as a reference gene for all samples to normalize the $\mathrm{Ct}$ values for the target gene. All experiments were carried out in the StepOne ${ }^{\mathrm{TM}}$ real-time PCR system (Applied Biosystems) (10).

Immunofluorescence. Immunofluorescence was performed after cytospin preparations (CitoSpin 2, Shandon) from K562 cells treated with $0.6 \mu \mathrm{M}$ vincristine for $0,2,6,8,18$ and $24 \mathrm{~h}$. Cells were fixed with $4 \%$ paraformaldehyde for $20 \mathrm{~min}$ and incubated with $10 \mathrm{mM} \mathrm{NH}_{4} \mathrm{Cl}$ for $10 \mathrm{~min}$. Subsequently, cells were permeabilized with $0.5 \%$ Triton $\mathrm{X}-100$, incubated in blocking solution (3\% BSA in PBS pH 8.0 and $0.1 \%$ Tween-20) for $2 \mathrm{~h}$, and overnight at $4^{\circ} \mathrm{C}$ with anti-Pgp (1:5 dilution, clone UIC2, Coulter, USA) or anti-survivin (1:900 dilution, Sigma Chemical). Afterwards the cells were incubated for $1 \mathrm{~h}$ at $37^{\circ} \mathrm{C}$ with Alexa 488-conjugated goat anti-rabbit IgG or with Alexa 594-conjugated goat anti-mouse IgG antibodies (1:100 dilution, Molecular Probe, Eugene, OR). After DNA staining with DAPI (4',6-diamidino-2-phenylindole) for $5 \mathrm{~min}$, glass slides were washed in PBS and mounted using n-propyl-gallate (27). Cell staining was visualized and registered in an Eclipse E200 Nikon microscope connected to a Digital Sight system. Images were captured by the NIS-Elements F2.30 software.

Statistical analysis. Statistical analysis of the results was performed using the Graph Pad Prism 4.0 software. Differences between vincristine-treated and untreated cells were analyzed by using Student's t-test or one-way analysis of variance (ANOVA). $\mathrm{p}<0.05$ was considered statistically significant.

\section{Results}

Effect of vincristine on K562 cells viability. We had previously demonstrated that treatment with increasing doses of vincristine through prolonged times induces an MDR phenotype on K562 cell lineage (28). Here, we evaluated the vincristine dose-response curve for K562 cells after $24 \mathrm{~h}$ of treatment. As shown in Fig. 1, treatment of K562 cells with 0.03, 0.06, 0.6, 1.0 and $2 \mu \mathrm{M}$ vincristine induced similar significant reduction on cell viability $(\mathrm{p}<0.05)$. Based on this result we used $0.6 \mu \mathrm{M}$ vincristine in the following experiments.

Vincristine inhibits cell cycle progression by inducing a G2/M phase arrest on $K 562$ cells. Vincristine is known to inhibit the assembly of microtubule structures, therefore blocking

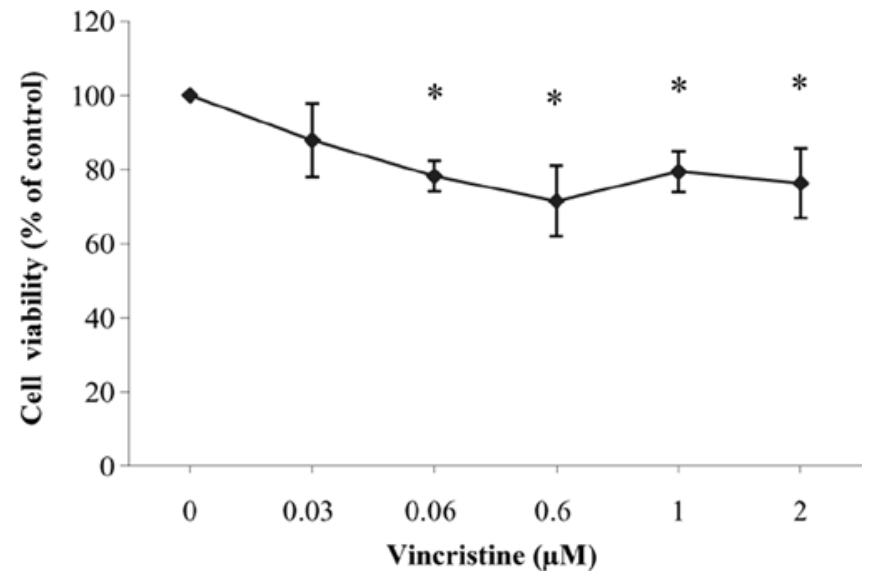

Figure 1. Vincristine induces a similar reduction on K562 cell viability. K562 cells were exposed to $0.03,0.06,0.6,1.0$ and $2 \mu \mathrm{M}$ vincristine and analyzed after $24 \mathrm{~h}$ by MTT assay. The results are representative of at least three independent experiments. ${ }^{*} \mathrm{p}<0.05$.

cell cycle progression (29). Based on this, we evaluated the effects of this drug on K562 cell cycle progression by exposing these cells to a high concentration of vincristine at different times. We observed a G2/M cell cycle arrest in K562 cells at 8,18 and $24 \mathrm{~h} \mathrm{(Fig.} \mathrm{2),} \mathrm{indicating} \mathrm{that} \mathrm{vincristine} \mathrm{treatment} \mathrm{is}$ capable of inhibiting K562 cell cycle progression.

Vincristine induces a low apoptotic index in K562 cells. We next investigated the effect of vincristine on K562 cells death through Annexin V/PI staining. As shown in Fig. 3A, vincristine treatment induced a low but significant apoptotic index only after $24 \mathrm{~h}(\mathrm{p}<0.05)$. In addition, we further analyzed pro-caspase- 3 cleavage by Western blotting. We observed a reduction of pro-caspase- 3 protein levels after $8 \mathrm{~h}$ of vincristine treatment (Fig. 3B), which may indicate caspase-3 activation. In contrast, flow cytometry analysis revealed caspase-3 activation only after $24 \mathrm{~h}$ (Fig. 3C), consistent with the Annexin V/PI results. These results suggest that the treatment with an elevated concentration of vincristine could not induce a high apoptotic index on K562 cells.

Vincristine induces a differential expression of survivin and XIAP in K562 cells. It has been reported that survivin or XIAP overexpression induces resistance to apoptosis in tumor cells $(19,30)$. Since vincristine was not able to induce a high apoptotic profile on K562 cells, we investigated the expression of XIAP and survivin in these cells upon vincristine treatment. A slight increase of XIAP expression was observed by Western blotting between 2 and $8 \mathrm{~h}$ (Fig. 4A). After that period, XIAP protein expression progressively decreased (Fig. 4A). Quantitative real-time PCR also revealed a similar increase of XIAP mRNA (Fig. 4B). In contrast to XIAP protein level reduction, survivin expression was progressively increased through vincristine treatment, with a remarkable overexpression at 18 and $24 \mathrm{~h}$ (Fig. 4A). These results indicate that survivin and XIAP are differently expressed during vincristine treatment in K562 cells, suggesting a differential role of these proteins in apoptosis regulation.

Subcellular localization of survivin varies upon vincristine treatment. Survivin plays a dual role as a key regulator of mitosis 
A

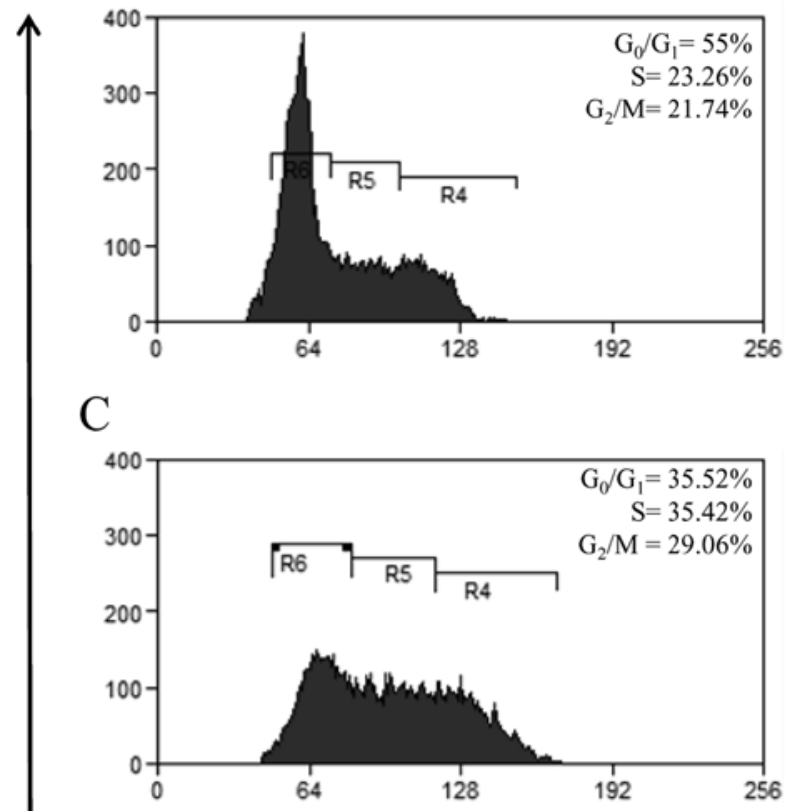

$\mathrm{E}$

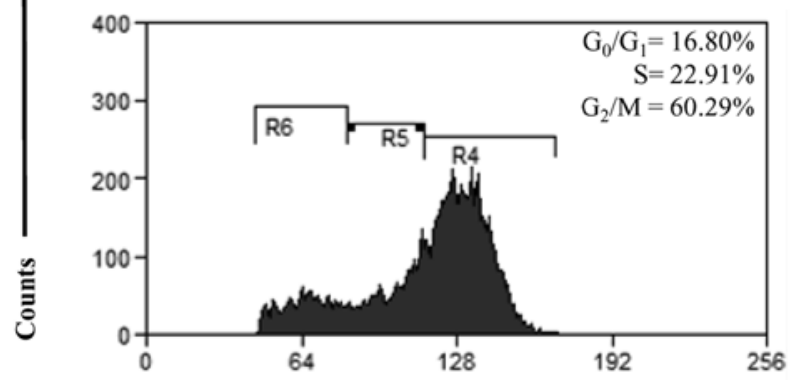

B

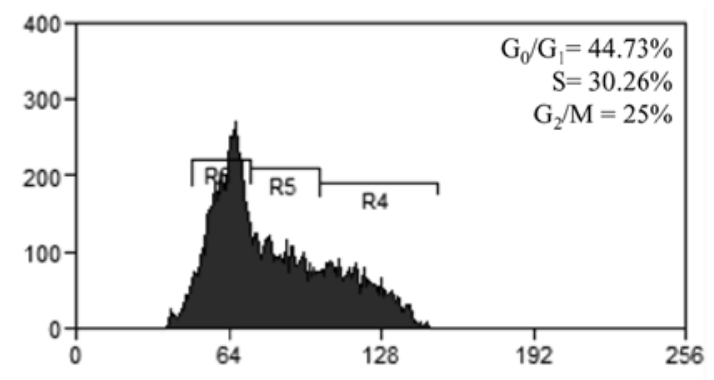

D

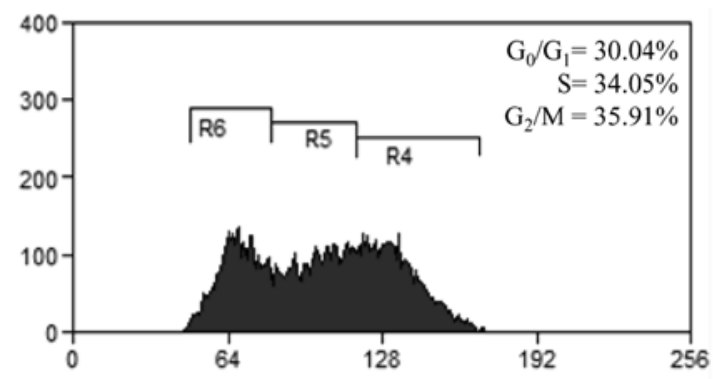

$\mathrm{F}$

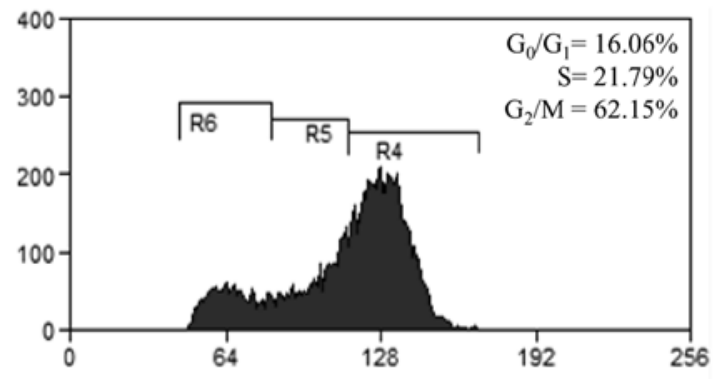

PI

Figure 2. Vincristine induces a G2/M phase arrest on K562 cells. K562 cells were exposed to $0.6 \mu \mathrm{M}$ vincristine at different times, stained with propidium iodide (PI), and then analyzed by flow cytometry. The percentage of cells in each phase of the cell cycle (G0/G1, S and G2/M) is indicated. (A-C) K562 cells progressed through the cell cycle (A) at 0 , (B) 2 and (C) $6 \mathrm{~h}$ independent drug treatment. (D-F) Vincristine inhibited cell cycle progression by inducing a G2/M phase arrest on K562 cells (D) at 8, (E) 18 and (F) 24 h. The results are representative of at least three independent experiments.

and apoptosis. When localized in the cytoplasm this protein acts as an anti-apoptotic protein, whereas in the nucleus survivin functions to regulate chromosome direction for spindle formation (31). The overexpression of survivin observed during vincristine treatment could be explained by cell cycle arrest in G2/M phase (Fig. 2). Therefore, we investigated the subcellular distribution of survivin in K562 cells treated with vincristine by immunofluorescence analysis. In untreated cells survivin was detected in both the nuclear and the cytoplasmic compartments (Fig. 5). At 2, 6 and $8 \mathrm{~h}$ of vincristine incubation, survivin was predominantly localized in the nucleus compared with control condition (Fig. 5). At later times (18 and $24 \mathrm{~h}$ ), survivin was upregulated and mostly localized in the cytoplasmic compartment (Fig. 5). These results suggest that survivin could be acting as an anti-apoptotic protein at 18 and $24 \mathrm{~h}$ of vincristine treatment.

$P$-glycoprotein expression is regulated by vincristine treatment in K562 cells. It has been reported that the MDR phenotype is multifactorial, and is related to simultaneous Pgp and IAP overexpression $(21,32)$. Moreover, other studies suggest an intimate relationship between survivin and Pgp expression in tumor cells $(21,22)$. For this reason, we also evaluated the expression of Pgp/ABCB1 mRNA in K562 cells upon vincristine treatment. As observed with survivin protein expression, treatment with vincristine induced a progressive increase in Pgp/ABCB1 mRNA expression after $8 \mathrm{~h}$ (Fig. 6A). In contrast, we did not observe significant Pgp protein expression on plasma membrane by extracellular immunostaining (Fig. 6B). Hence, we investigated the subcellular localization of Pgp protein by immunofluorescence analysis at indicated times. Although we could not observe Pgp staining in untreated cells (Fig. 6C), after $8 \mathrm{~h}$ of vincristine treatment Pgp was predominantly detected in the nuclear membrane. In addition, at 18 and $24 \mathrm{~h}$ K562 cells displayed a nuclear and cytoplasmic localization of Pgp protein. These data suggest that Pgp is regulated by vincristine treatment and might also perform an anti-apoptotic role in K562 cells. 
A

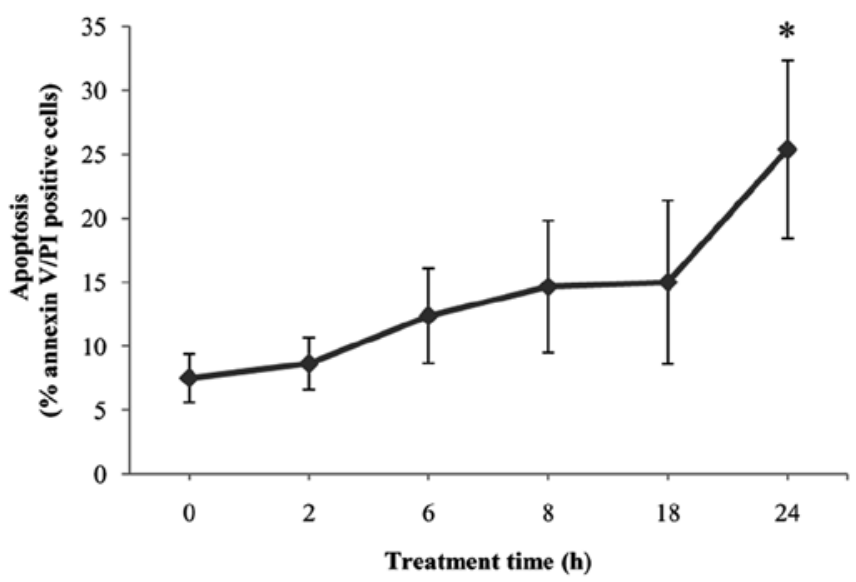

B

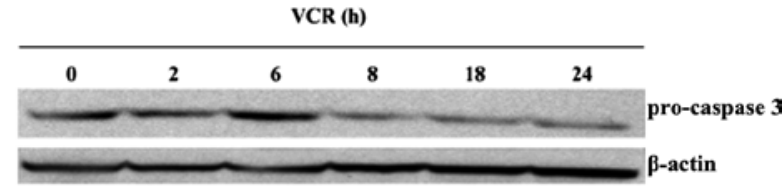

$\mathrm{C}$

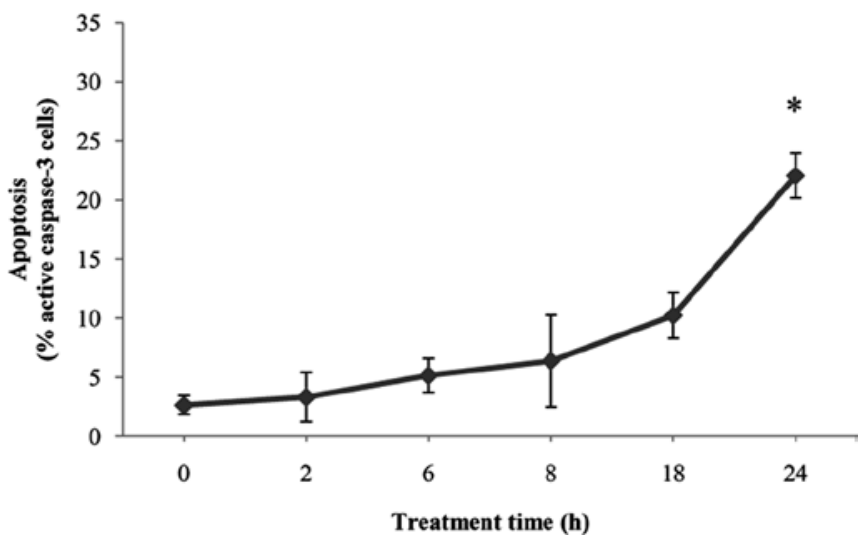

Figure 3. K562 cells undergo a low apoptotic index even at a high concentration of vincristine treatment. K562 cells were exposed to $0.6 \mu \mathrm{M}$ vincristine at different times and analyzed for cell death. (A) K562 cells were stained with Annexin V/PI and analyzed by flow cytometry at different times. Vincristine treatment induced a low but significant apoptotic index only after $24 \mathrm{~h}(\mathrm{p}<0.05)$. (B) Western blotting for pro-caspase-3. The antibody used only recognizes the pro-form of caspase-3. K562 cells obtained a reduction of pro-caspase- 3 protein levels after $8 \mathrm{~h}$ of drug treatment. $\beta$-actin detection was used as a load control. (C) Analysis of caspase-3-activated expression by flow cytometry using anti-caspase-3-PE antibody. Vincristine treatment induced caspase-3 activation only after $24 \mathrm{~h}(\mathrm{p}<0.05)$. All results are representative of at least three independent experiments.

\section{Discussion}

The MDR phenotype is commonly attributed to the elevated expression of Pgp and its function as a drug efflux pump. The development of MDR is mainly related to anticancer treatment. Emerging roles for Pgp in apoptosis inhibition have drawn much attention, but relatively little is known about the role of Pgp in this type of function. On the other hand, survivin, a member of the IAP family, has a well-known role as an apop- tosis inhibitor and has also been associated with resistance to chemotherapeutic drugs $(32,33)$.

In this study, we demonstrated that vincristine was not able to induce a high apoptotic index in the sensitive CML cell lineage K562. Furthermore, concomitant overexpression of $\mathrm{Pgp} / A B C B 1$ and survivin in K562 cells reduced cell death even under high chemical stress in these cells, which suggests a functional association between these two proteins. Additionally, the co-localization of Pgp and survivin in the cytoplasmatic compartment reinforces this hypothesis.

Different mechanisms induce the MDR phenotype in cancer cells. K562 is a sensitive CML cell lineage, which does not express the MDR phenotype. In our study, however, K562 cells displayed a resistant behavior during vincristine treatment. Recently, a study demonstrated that MDR could be acquired through intercellular transfer of Pgp in co-culture of sensitive and resistant versions of some cell lines $(34,35)$. In contrast, in this current study we induced overexpression of $\mathrm{Pgp} / A B C B 1$ over a short time of vincristine exposure in K562 cells, which did not previously express Pgp/ABCB1 protein or mRNA. Our data are supported by a study that showed the upregulation of $A B C B 1$ in a human drug-resistant leukemia cell line by anthracycline treatment (36). We had also previously demonstrated that long treatment with increasing doses of vincristine induces an MDR phenotype on K562 cell lineage (28). In fact, several anticancer drugs may induce Pgp expression and as a result promote MDR features. Basically, the mechanism of Pgp induction involves PXR-mediated Pgp translation through the activation of PXR by many anticancer drugs (37). Beyond that, several transcription factors and cofactors such YB-1, NF-Y, MEF-1, HSF-1 and others cooperate in Pgp regulation (38-41).

In MDR tumor cells Pgp is mainly located in the plasma membrane, although some studies have shown Pgp expression in the nuclear envelope and in the membrane of cytoplasmic organelles $(42,43)$. Here, we showed for the first time that vincristine treatment induced a differential subcellular localization of Pgp in K562 cells. Our data describe an initial expression of Pgp in the nuclear envelope that spreads over to the cytosol during vincristine treatment. A recent study suggests that Pgp proteins located in the nuclear envelope may be involved in the removal of drugs from the nucleus and that cytoplasmic Pgp may contribute to transport outwards the cells (44). According to these data, we can suppose in our study that nuclear and cytosolic Pgp contributed to the defense mechanism in K562 cells against vincristine. Additionally, we also suggest that cytosolic Pgp might perform an anti-apoptotic role due to its co-localization with survivin in K562 cells.

So far, only a few studies discuss the possible association between Pgp and survivin. Consistent with our data, however, a recent study demonstrated that inhibition of Pgp is associated with a downregulation of survivin (21). In accordance with this, another recent report showed that survivin transcription is associated with overexpression of Pgp (22).

Although it has been demonstrated that there is no direct binding between Pgp and survivin (45), these proteins have common regulators, which may suggest a similar regulatory pathway. The cell survival/anti-apoptotic pathways have been associated with expression of some MDR proteins (46). In addition, a recent study has shown the involvement of the PI3K 
A

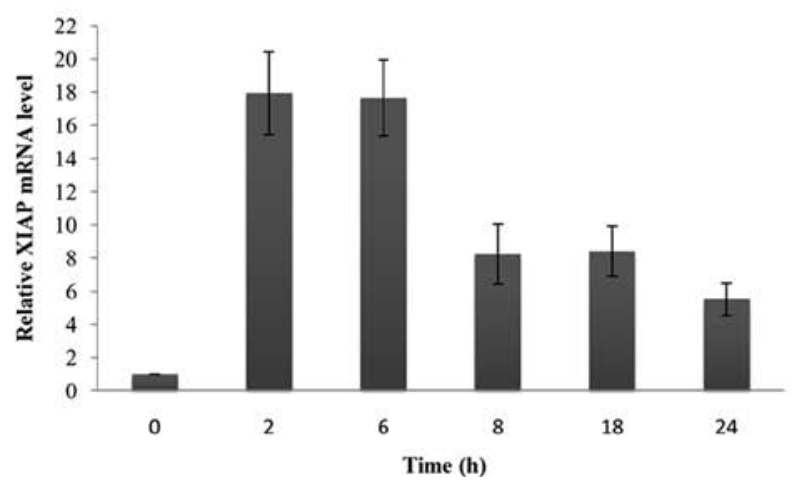

B

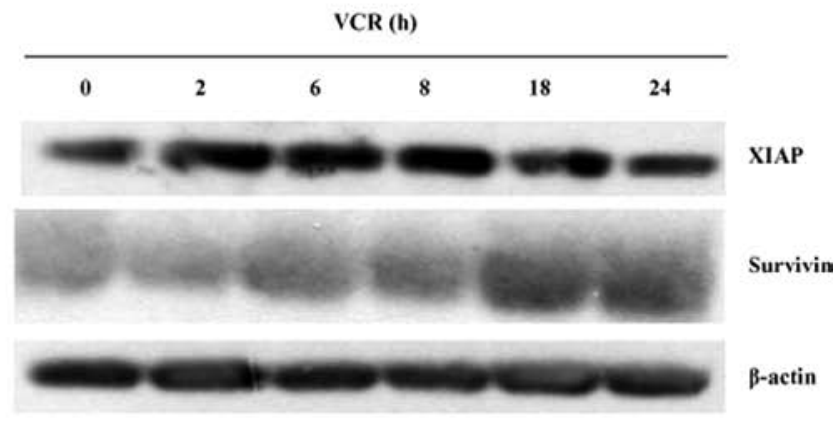

Figure 4. Modulation of survivin and XIAP expression in K562 cells after treatment with vincristine. K562 cells were exposed to $0.6 \mu$ M vincristine at different times, and survivin and XIAP expression levels were analyzed by Western blotting or quantitative RT-PCR. (A) Western blotting for survivin and XIAP. Cell extracts were obtained after each time of vincristine treatment and then stained with survivin, XIAP and $\beta$-actin anti-bodies. $\beta$-actin detection was used as a load control. (B) Quantitative real-time PCR for XIAP. Levels of XIAP mRNA in K562 cells treated with vincristine were analyzed by quantitative RT-PCR. All results are representative of at least three independent experiments.

$\mathbf{0 ~ h}$
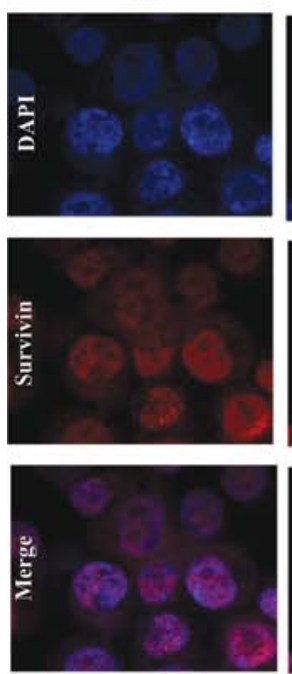

2 h
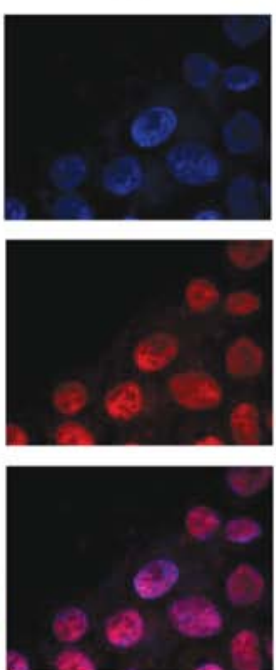

$6 \mathrm{~h}$
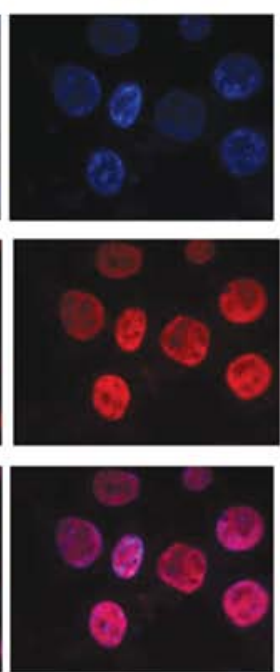

8 h
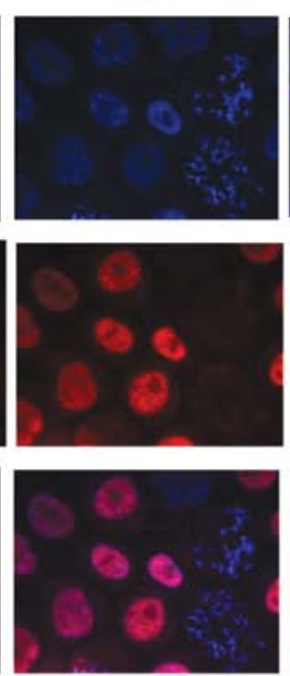

$18 \mathrm{~h}$
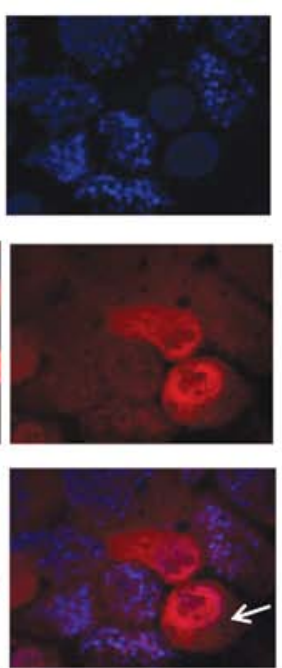

24 h
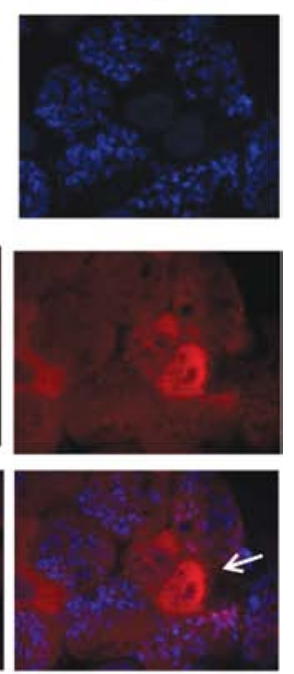

Figure 5. Survivin localization changes upon vincristine treatment in K562 cells. K562 cells were treated with $0.6 \mu \mathrm{M}$ vincristine at different times, stained with DAPI (blue) and anti-survivin (red) antibody, and then analyzed by immunofluorescence. Arrows indicate survivin localized in the cytoplasmatic compartment. Original magnification, x1000. The results are representative of at least three independent experiments.

signaling pathway in the regulation of Pgp and survivin expression (22). It was demonstrated that the active form of PI3K is related to an increase of Pgp expression (46). Furthermore, several molecular pathways, such as NF- $\mathrm{B}$, ERK/MAPK, and p38-MAPK, among others, are also associated with the regulation of Pgp expression in cancer cells (47-49). A recent study showed that the MDR phenotype in K562 cells could be reversed by inhibition of the $N F-\kappa B$ pathway, suggesting a regulation of Pgp through modulation of NF- $\kappa \mathrm{B}(50)$. NF- $\kappa \mathrm{B}$ activation also contributes to survivin expression, and likewise NF- $\kappa \mathrm{B}$ inhibition downregulates survivin $(51,52)$. The expression of survivin is regulated by several other molecular pathways such as mTOR, which is required for its stability and translation (53). Furthermore, it is important to note that some drugs may induce expression of survivin by activation of the PI3K pathway (54).
Published works have shown that survivin can be negatively regulated by wild-type p53 and positively regulated by mutant p53 in many cancer cells $(56,57)$. p53 is also related to regulation of Pgp. A study on the mechanism of Pgp regulation revealed that wild-type p53 can reverse the MDR phenotype through inhibition of PKC $\alpha$ (57). In addition, cells expressing mutant p53 show the MDR phenotype based on the fact that it is able to activate the $A B C B 1$ promoter (58). According to all these reports, we support the idea that Pgp and survivin could regulate and contribute to reduce cell death by a common mechanism.

Some molecular pathways that regulate survivin are common for other IAPs. Although the activation of $\mathrm{NF}-\kappa \mathrm{B}$ also relates to the upregulation of XIAP (51), our experimental data indicated that expression of XIAP in K562 cells by vincristine treatment changed unrelated to Pgp expression, suggesting that apoptosis 


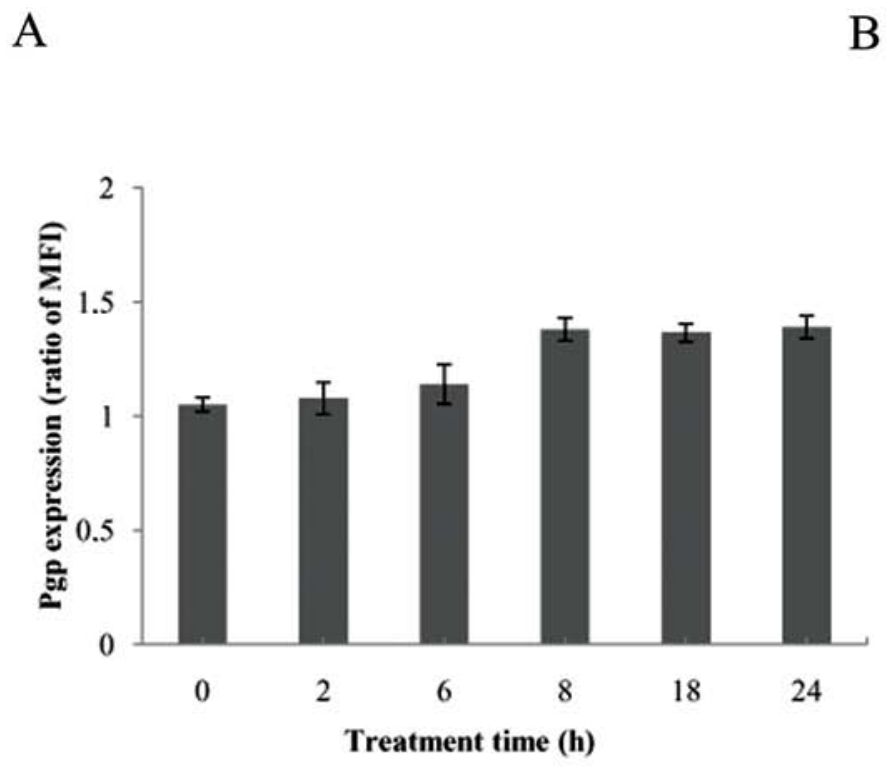

$\mathrm{C}$

B
$8 \mathrm{~h}$
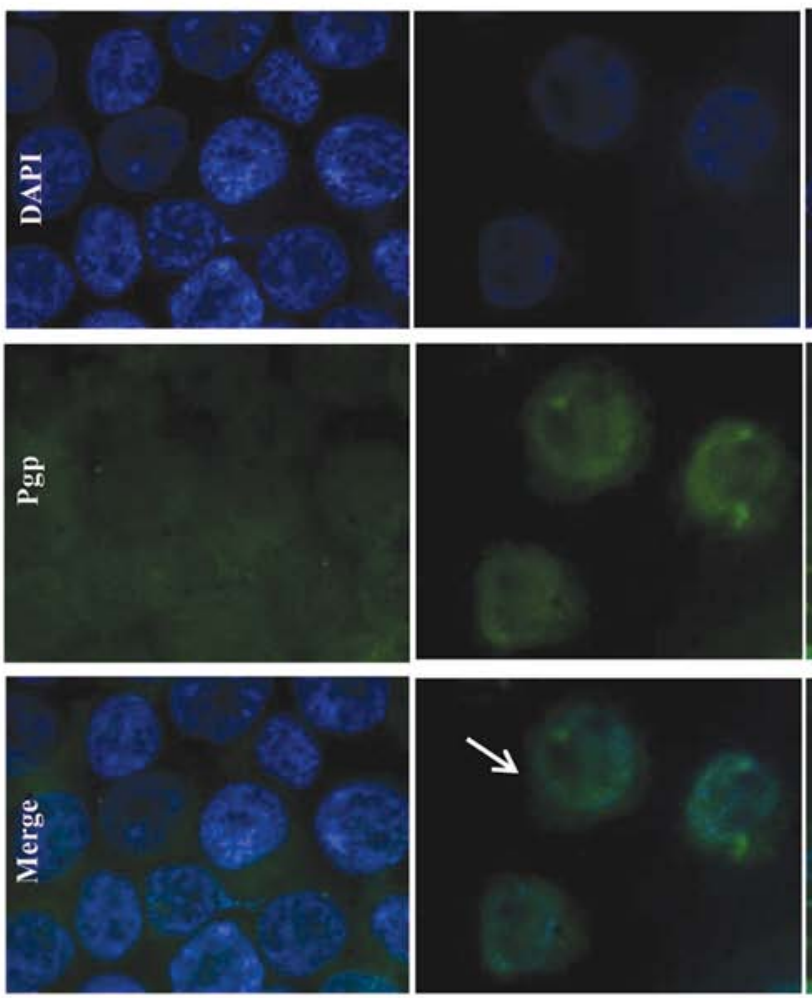

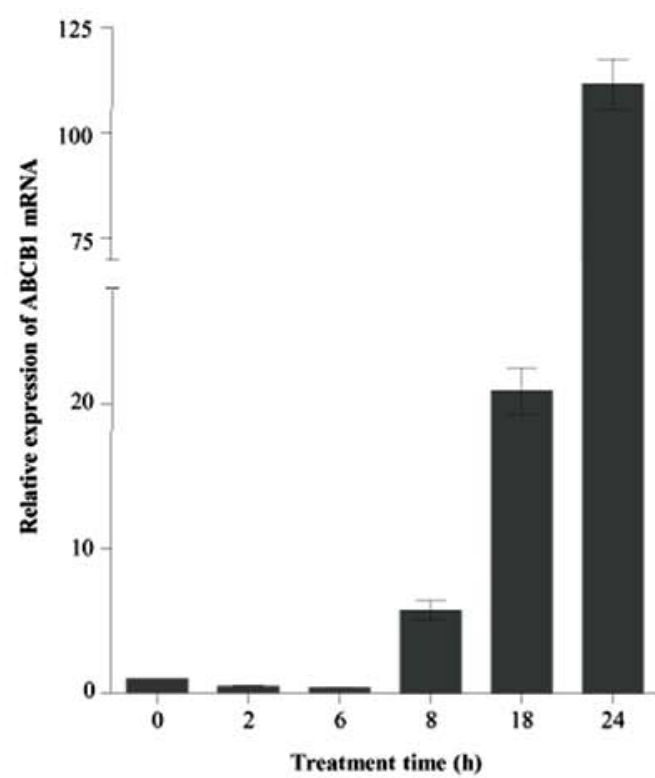

$18 \mathrm{~h}$
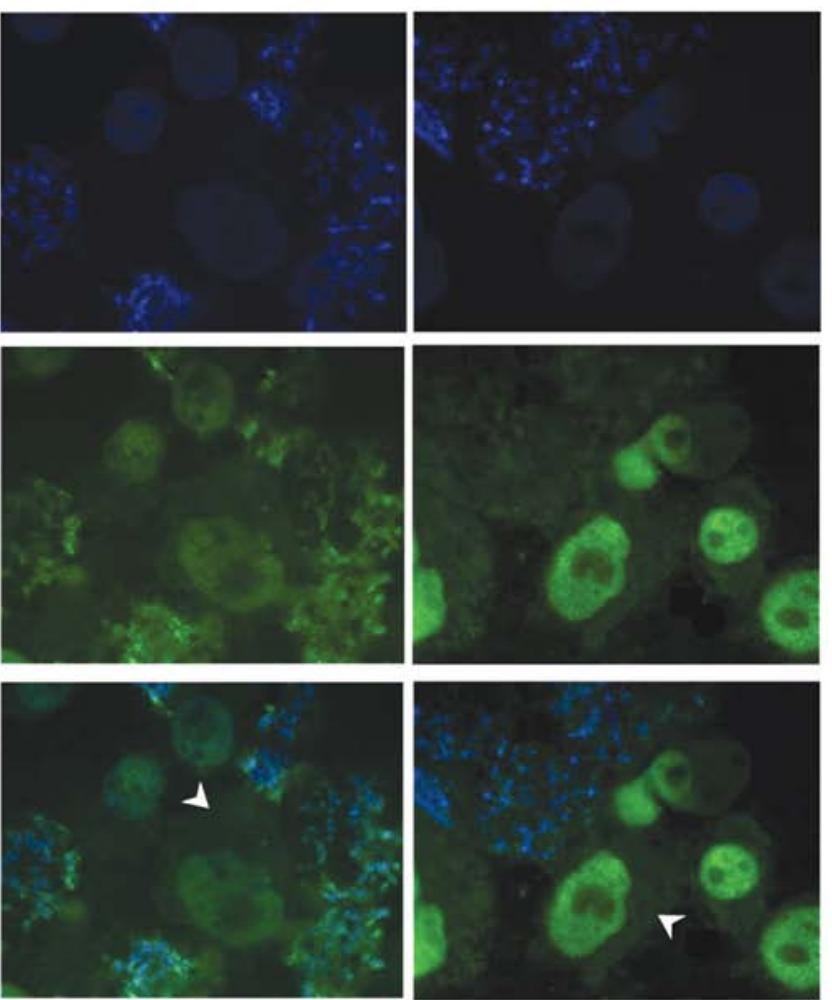

Figure 6. Modulation of P-glycoprotein (Pgp) expression in K562 cells after treatment with vincristine. K562 cells were exposed to $0.6 \mu \mathrm{M}$ vincristine at different times, and Pgp expression was analyzed by quantitative RT-PCR, flow cytometry and immunofluorescence. (A) Analysis of extracellular Pgp expression by flow cytometry using anti-Pgp antibody. (B) Quantitative real-time PCR for ABCB1. Levels of ABCB1 mRNA in K562 cells treated with vincristine were analyzed by quantitative RT-PCR. (C) K562 cells treated with vincristine were stained with DAPI (blue) and anti-Pgp antibody (green) and then analyzed by immunofluorescence. Arrow head indicates Pgp localized in nuclear membrane; arrows indicate Pgp localized in the cytoplasmatic compartment. Original magnification, $x 1000$. All results are representative of at least three independent experiments.

resistance promoted by XIAP and Pgp occurs by an independent mechanism. In addition, our data are in concordance with a recent report that demonstrated that inhibition of Pgp did not change XIAP mRNA and protein levels in chondrosarcoma cells, although simultaneous inhibition of Pgp and XIAP is needed to prevent cell survival more efficiently (59).

In conclusion, we demonstrated that a high dose of vincristine induces simultaneously an upregulation of survivin and a 
de novo expression of Pgp in the classic sensitive K562 CML cell line. This induced MDR phenotype prevented overwhelming cell death, which suggests a functional association between these two proteins by a common mechanism. Moreover, our data also suggest that cytosolic Pgp might perform an antiapoptotic role.

\section{Acknowledgements}

This work was supported by grants from Swissbridge Foundation, INCT para Controle do Câncer, CNPq 573806/2008-0; FAPERJ EE26/170.026/2008 e Programa de Oncobiologia (UFRJ e Fundação do Câncer). The authors thank André Luiz de Souza $\mathrm{Cruz}, \mathrm{MSc}$, for his help in immunofluorescence assay.

\section{References}

1. Gottesman MM, Fojo T and Bates SE: Multidrug resistance in cancer: role of ATP-dependent transporters. Nat Rev Cancer 2: 48-58, 2002.

2. Kruh GD: Introduction to resistance to anticancer agents. Oncogene 22: 7262-7264, 2003.

3. Carter A, Dann EJ, Katz T, et al: Cells from chronic myelogenous leukaemia patients at presentation exhibit resistance not mediated by either MDR1 or MRP1. Br J Haematol 114: 581-590, 2001.

4. Van der Borght S, Komuta M, Libbrecht L, et al: Expression of multidrug resistance-associated protein 1 in hepatocellular carcinoma is associated with a more aggressive tumour phenotype and may reflect a progenitor cell origin. Liver Int 28: 1370-1380, 2008

5. Kourti M, Vavatsi N, Gombakis N, et al: Expression of multidrug resistance 1 (MDR1), multidrug resistance-related protein 1 (MRP1), lung resistance protein (LRP), and breast cancer resistance protein (BCRP) genes and clinical outcome in childhood acute lymphoblastic leukemia. Int J Hematol 86: 166-173, 2007.

6. Szakacs G, Chen GK and Gottesman MM: The molecular mysteries underlying P-glycoprotein-mediated multidrug resistance. Cancer Biol Ther 3: 382-384, 2004.

7. Loo TW and Clarke DM: Recent progress in understanding the mechanism of P-glycoprotein-mediated drug efflux. J Membr Biol 206: 173-185,2005.

8. Sonneveld P: Multidrug resistance in haematological malignancies. J Intern Med 247: 521-534, 2000.

9. Chen Y, Tang Y, Wang MT, Zeng S and Nie D: Human pregnane $\mathrm{X}$ receptor and resistance to chemotherapy in prostate cancer. Cancer Res 67: 10361-10367, 2007.

10. Vasconcelos FC, Silva KL, Souza PS, Silva LFR, MoellmannCoelho A, Klumb CE and Maia RC: Variation of MDR proteins expression and activity levels according to clinical status and evolution of CML patients. Cytometry B Clin Cytom (In press).

11. Molinari A, Calcabrini A, Meschini S, et al: Subcellular detection and localization of the drug transporter P-glycoprotein in cultured tumor cells. Curr Protein Pept Sci 3: 653-670, 2002.

12. Robinson LJ, Roberts WK, Ling TT, Lamming D, Sternberg SS and Roepe PD: Human MDR 1 protein overexpression delays the apoptotic cascade in Chinese hamster ovary fibroblasts. Biochemistry 36: 11169-11178, 1997.

13. Smyth MJ, Krasovskis E, Sutton VR and Johnstone RW: The drug efflux protein, P-glycoprotein, additionally protects drugresistant tumor cells from multiple forms of caspase-dependent apoptosis. Proc Natl Acad Sci USA 95: 7024-7029, 1998.

14. Johnstone RW, Cretney E and Smyth MJ: P-glycoprotein protects leukemia cells against caspase-dependent, but not caspaseindependent, cell death. Blood 93: 1075-1085, 1999.

15. Ruefli AA, Tainton KM, Darcy PK, Smyth MJ and Johnstone RW: P-glycoprotein inhibits caspase- 8 activation but not formation of the death inducing signal complex (disc) following Fas ligation. Cell Death Differ 9: 1266-1272, 2002.

16. Pallis M, Turzanski J, Seedhouse C and Russel N: Resistance to spontaneous apoptosis in acute myeloid leukaemia blasts is associated with P-glycoprotein expression and function, but not with the presence of FLT3 internal tandem duplications. Br J Haematol 120: 1009-1016, 2003.
17. Shman TV, Fedasenka UU, Savitski VP and Aleinikova OV: $\mathrm{CD} 34^{+}$leukemic subpopulation predominantly displays lower spontaneous apoptosis and has higher expression levels of Bcl-2 and MDR1 genes than CD34- cells in childhood AML. Ann Hematol 87: 353-360, 2008

18. Wang X, Wang C, Qin YW, Yan SK and Gao YR: Simultaneous suppression of multidrug resistance and antiapoptotic cellular defense induces apoptosis in chemoresistant human acute myeloid leukemia cells. Leuk Res 31: 989-994, 2007.

19. Fukuda $S$ and Pelus LM: Survivin a cancer target with an emerging role in normal adult tissues. Mol Cancer Ther 5: 1087-1098, 2006.

20. Conte E, Stagno F, Guglielmo P, Scuto A, Consoli C and Messina A: Survivin expression in chronic myeloid leukemia. Cancer Lett 225: 105-110, 2005.

21. Liu F, Xie ZH, Cai GP and Jiang YY: The effect of survivina on multidrug resistance cells P-glycoprotein in MCF-7 and its adriamycin cells. Biol Pharm Bull 30: 2279-2283, 2007.

22. Liu F, Liu S, He S, Xie Z, Zu X and Jiang Y: Survivin transcription is associated with P-glycoprotein/MDR1 overexpression in the multidrug resistance of MCF-7 breast cancer cells. Oncol Rep 23: 1469-1475, 2010.

23. Mosman T: Rapid colorimetric assay for cellular growth and survival: application to proliferation and cytotoxicity assays. J Immunol Methods 65: 55-63, 1983.

24. Silva KL, Flavia C, Vasconcelos FC, Marques-Santos LF, Kwee JK and Maia RC: CPT-11-induced cell death in leukemic cells is not affected by the MDR phenotype. Leuk Res 27: 243-251, 2003.

25. Vasconcelos FC, Gattass CR, Rumjanek VM and Maia RC: Pomolic acid-induced apoptosis in cells from patients with chronic myeloid leukemia exhibiting different drug resistance profile. Invest New Drugs 25: 525-533, 2007.

26. Maia RC, Vasconcelos FC, de Sá Bacelar T, et al: LQB-118, a pterocarpanquinone structurally related to lapachol [2-hydroxy3-(3-methyl-2-butenyl)-1,4-naphthoquinone]: a novel class of agent with high apoptotic effect in chronic myeloid leukemia cells. Invest New Drugs (In press).

27. Vidal F, de Araújo WM, Cruz AL, Tanaka MN, Viola JP and Morgado-Diaz JA: Lithium reduces tumorigenic potential in response to EGF signaling in human colorectal cancer cells. Int J Oncol 38: 1365-1373, 2011.

28. Rumjanek VM, Trindade GS, Wagner-Souza K, Meletti-deOliveira MC, Marques-Santos LF, Maia RC and Capella MAM: Multidrug resistance in tumour cells: characterization of the multidrug resistant cell line K562-Lucena 1. An Acad Bras Cienc 73: 57-69, 2001.

29. McGrogan BT, Gilmartin B, Carney DN and McCann A: Taxanes, microtubules and chemoresistant breast cancer. Biochim Biophys Acta 1785: 96-132, 2008.

30. Schimmer AD, Dalili S and Ried SJ: Targeting XIAP for the treatment of malignancy. Cell Death Differ 13: 179-188, 2006.

31. Mita AC, Mita MM, Nawrocki ST and Gilles FJ: Survivin: key regulator of mitosis and apoptosis and novel target for cancer therapeutics. Clin Cancer Res 14: 5000-5005, 2008.

32. Notarbartolo M, Cervello M, Dusonchet L, Cusimano A and D'Alessandro N: Resistance to diverse apoptotic triggers in multidrug resistant HL60 cells and its possible relationship to the expression of P-glycoprotein, Fas and of the novel ani-apoptosis factors IAP (inhibitory of apoptosis proteins). Cancer Lett 180: 91-101, 2002.

33. Notarbartolo M, Cervello M, Poma P, Dusonchet L, Meli M and D'Alessandro N: Expression of the IAPs in multidrug resistant tumor cells. Oncol Rep 11: 133-136, 2004.

34. Levchenko A, Mehta BM, Niu X, et al: Intercellular transfer of P-glycoprotein mediates acquired multidrug resistance in tumor cells. Proc Natl Acad Sci USA 102: 1933-1938, 2005.

35. Bebawy M, Combes V, Lee E, Jaiswal R, Gong J, Bonhoure A and Grau GE: Membrane microparticles mediate transfer of P-glycoprotein to drug sensitive cancer cells. Leukemia 23: 1643-1649, 2009.

36. Hu XF, Slater A, Rischin D, Kantharidis P, Parkin JD and Zalcberg J: Induction of MDR1 gene expression by anthracycline analogues in a human drug resistant leukaemia cell line. Br J Cancer 79: 831-837, 1999.

37. Harmsen S, Meijerman I, Febus CL, Maas-Bakker RF, Beijnen JH and Schellens JHM: PXR-mediated induction of P-glycoprotein by anticancer drugs in a human colon adenocarcinoma-derived cell line. Cancer Chemother Pharmacol 66: 765-771, 2010. 
38. Vilaboa NE, Galán A, Troyano A, de Blas E and Aller P: Regulation of multidrug resistance 1 (MDR1)/P-glycoprotein gene expression and activity by heat-shock transcription factor 1 (HSF1). J Biol Chem 275: 24970-24976, 2000.

39. Zhong $X$ and Safa AR: RNA helicase A in the MEF1 transcription factor complex up-regulates the MDR1 gene in multidrug-resistant cancer cells. J Biol Chem 279: 17134-17141, 2004.

40. Kuwano M, Oda Y, Izumi H and Yang S-J: The role of nuclear Y-box binding protein 1 as a global marker in drug resistance. Mol Cancer Ther 3: 1485-1492, 2004.

41. $\mathrm{Hu} \mathrm{Z}$, Jin S and Scotto KW: Transcriptional activation of the MDR1 gene by UV irradiation. Role of NF-Y and Sp1. J Biol Chem 275: 2979-2985, 2000.

42. Arancia G, Molinari A, Calcabrini A, Meschini S and Cianfriglia M: Intracellular P-glycoprotein in multidrug resistant tumor cells. Ital J Anat Embryol 106: 59-68, 2001

43. Calcabrini A, Meschini S, Stringaro A, Cianfriglia M, Arancia G and Molinari A: Detection of P-glycoprotein in the nuclear envelope of multidrug resistant cells. Histochem J 32: 599-606, 2000.

44. Argova M, Boda T, Batrab S and Margalit R: Novel steroid carbamates reverse multidrug-resistance in cancer therapy and show linkage among efficacy, loci of drug action and P-glycoprotein's cellular localization. Eur J Pharm Sci 41: 53-59, 2010.

45. Shi Z, Liang YJ, Chen ZS, Wang XH, Ding Y, Chen LM and Fu LW: Overexpression of survivin and XIAP in MDR cancer cells unrelated to P-glycoprotein. Oncol Rep 17: 969-976, 2007.

46. Misra S, Ghatak S and Toole BP: Regulation of MDR1 expression and drug resistance by a positive feedback loop involving hyaluronan, phosphoinositide 3-kinase, and ErbB2. J Biol Chem 280: 20310-20315, 2005.

47. Kuo MT, Liu Z, Wei Y Lin-Lee YC, Tatebe S, Mills GB and Unate H: Induction of human MDR1 gene expression by 2-acetylaminofluorene is mediated by effectors of the phosphoinositide 3-kinase pathway that activate NF-kappaB signaling. Oncogene 21: 1945-1954, 2002.

48. Guan J, Chen XP, Zhu H, Luo SF, Cao B and Ding L: Involvement of extracellular signal-regulated kinase/mitogen-activated protein kinase pathway in multidrug resistance induced by $\mathrm{HBx}$ in hepatoma cell line. World J Gastroenterol 10: 3522-3527, 2004.
49. Guo X, Ma N, Wang J, et al: Increased p38-MAPK is responsible for chemotherapy resistance in human gastric cancer cells. BMC Cancer 8: 375, 2008.

50. Assef Y, Rubio F, Coló G, del Mónaco S, Costas MA and Kotsias BA: Imatinib resistance in multidrug-resistant K562 human leukemic cells. Leuk Res 33: 710-716, 2009.

51. Kawakami H, Tomita M, Matsuda T, et al: Transcriptional activation of survivin through the NFkappaB pathway by human T-cell leukemia virus type I tax. Int J Cancer 115: 967-974, 2005

52. Tracey L, Perez-Rosado A, Artiga MJ, et al: Expression of the NF-kappaB targets BCL2 and BIRC5/Survivin characterizes small B-cell and aggressive B-cell lymphomas, respectively. J Pathol 206: 123-134, 2005.

53. Vaira V, Lee CW, Goel HL, Bosari S, Languino LR and Altieri DC: Regulation of survivin expression by IGF-1/mTOR signaling. Oncogene 26: 2678-2684, 2007.

54. Wang Q and Greene MI: EGFR enhances survivin expression through the phosphoinositide 3 (PI-3) kinase signaling pathway. Exp Mol Pathol 79: 100-107, 2005.

55. Tsuji N, Furuse K, Asanuma K, et al: Mutations of the p53 gene and loss of heterozygosity at chromosome $17 \mathrm{p} 13.1$ are associated with increased survivin expression in breast cancer. Breast Cancer Res Treat 87: 23-31, 2004.

56. Nakano J, Huang CL, Liu D, Ueno M, Sumitomo S and Yokomise H: Survivin gene expression is negatively regulated by the p53 tumor suppressor gene in non-small cell lung cancer. Int J Oncol 27: 1215-1221, 2005.

57. Zhan M, Yu D, Liu J, Glazer RI, Hannay J and Pollock RE: Transcriptional repression of protein kinase Calpha via Sp1 by wild type p53 is involved in inhibition of multidrug resistance 1 P-glycoprotein phosphorylation. J Biol Chem 280: 4825-4833, 2005.

58. Thottassery JV, Zambetti GP, Arimori K, Schuetz EG and Schuetz JD: p53-dependent regulation of MDR1 gene expression causes selective resistance to chemotherapeutic agents. Proc Natl Acad Sci USA 94: 11037-11042, 1997.

59. Kim DW, Kim K-O, Shin MJ, Ha JH, Seo SW, Yang J and Lee FY: siRNA-based targeting of antiapoptotic genes can reverse chemoresistance in P-glycoprotein expressing chondrosarcoma cells. Mol Cancer 8: 1-10, 2009. 